Article

\title{
Surfactant-Enhanced Solubilization of Chlorinated Organic Compounds Contained in DNAPL from Lindane Waste: Effect of Surfactant Type and $\mathrm{pH}$
}

\author{
Raúl García-Cervilla ${ }^{\circledR}$, Arturo Romero, Aurora Santos and David Lorenzo * \\ Chemical and Materials Engineering Department, University Complutense of Madrid, 28040 Madrid, Spain; \\ raugar05@ucm.es (R.G.-C.); aromeros@quim.ucm.es (A.R.); aursan@quim.ucm.es (A.S.) \\ * Correspondence: dlorenzo@quim.ucm.es
}

Received: 20 May 2020; Accepted: 19 June 2020; Published: 23 June 2020

check for updates

\begin{abstract}
Application of surfactants in the remediation of polluted sites with dense nonaqueous phase liquid (DNAPL) still requires knowledge of partitioning between surfactants and pollutants in the organic and aqueous phases and the time necessary to reach this balance. Two real DNAPLs, generated as wastes in the lindane production and taken from the polluted sites from Sabiñanigo (Spain), were used for investigating the solubilization of 28 chlorinated organic compounds (COCs) applying aqueous surfactant solutions of three nonionic surfactants (E-Mulse ${ }^{\circledR} 3$ (E3), Tween ${ }^{\circledR} 80$ (T80), and a mixture of Tween ${ }^{\circledR} 80-S_{\text {Span }}{ }^{\circledR} 80$ (TS80)) and an anionic surfactant (sodium dodecyl sulfate (SDS)). The initial concentrations of surfactants were tested within the range of $3-17 \mathrm{~g} \cdot \mathrm{L}^{-1}$. The $\mathrm{pH}$ was also modified from 7 to $>12$. The uptake of nonionic surfactants into the organic phase was higher than the anionic surfactants. Solubilization of COCs with the nonionic surfactants showed similar molar solubilization ratios $\left(\mathrm{MSR}=4.33 \mathrm{mmol}_{C O C s} \cdot \mathrm{g}^{-1}{ }_{\text {surf }}\right)$, higher than SDS $\left(\mathrm{MSR}=0.70 \mathrm{mmol}_{C O C s} \cdot \mathrm{g}^{-1}{ }_{S D S}\right)$. Furthermore, under strong alkaline conditions, the MSR value of the nonionic surfactants was unchanged, and the MSR of SDS value increased $\left(\mathrm{MSR}=1.32 \mathrm{mmol}_{C O C_{s}} \cdot \mathrm{g}^{-1}{ }_{S D S}\right)$. The nonionic surfactants did not produce preferential solubilization of COCs; meanwhile, SDS preferentially dissolved the more polar compounds in DNAPL. The time required to reach phase equilibrium was between 24 and $48 \mathrm{~h}$, and this contact time should be assured to optimize the effect of the surfactant injected on COC solubilization.
\end{abstract}

Keywords: DNAPL; surfactants; partition; lindane wastes; chlorinated organic compounds

\section{Introduction}

Contamination of soil and groundwater by organic compounds from industrial activities has become a major environmental problem [1]. This contamination is often due to the accidental release or intentional dumping of hydrophobic organic liquid phases into the environment, resulting in a separate liquid phase, referred to as nonaqueous phase liquids (or NAPLs), that persists in the subsurface [2]. Nonaqueous Phase Liquids are hydrophobic organic phases that show properties and behavior other than dissolving contaminant plumes. NAPLs whose density is lower than that of water are light NAPLs (LNAPLs) [3,4], and NAPLs with a higher density than water are called dense nonaqueous phase liquids (DNAPL).

DNAPLs include common industrial solvents (trichloroethylene, perchloroethylene, carbon tetrachloride, dichloromethane) or other hazardous substances such as creosote and coal tar. Other chlorinated organic pollutants forming DNAPLs include pesticides and chlorinated compounds used for their synthesis [5-7]. Most of these DNAPLs are persistent in the environment due to their hydrophobic nature and low biodegradability, characterized by high toxicity and bioaccumulation and, 
in some cases, carcinogenesis [8]. DNAPLs can migrate by density through the subsurface to greater depths, and a significant mass of DNAPL can be trapped in the soil pores $[9,10]$ or soil fractures $[5,11]$.

The remediation of sites polluted by DNAPLs poses essential technical and economic challenges. Conventional treatment technologies such as pump and treat have potentially high life cycle costs [12,13], and a feasible solution to improve the solubilization and mobilization of these DNAPLs is the Soil Flushing treatment where an aqueous solution containing the surfactant (with other possible amendments) is injected into the subsurface and then extracted and treated on-site [14-22].

Surfactants are amphiphilic compounds, and the hydrophilic group is an ionic (cationic, anionic) or highly polar group (nonionic) [23]. When a surfactant is added to the aqueous phase, surface tension decreases as surfactant concentration increases until the critical micelle concentration (CMC) is reached. At this point, tension remains constant as more and more surfactant is added to the solution [24]. However, although surface tension remains constant, the concentration of solubilized chlorinated organic compounds (COCs) increases when the concentration of surfactants in the solution increases [25].

Therefore, the equilibrium of the compounds presented in the DNAPL between the aqueous and the organic phase must be known for a reliable design of the Soil Flushing remediation treatment. This equilibrium is modeled using the mass solubilization ratio (WSR) or molar solubilization ratio (MSR). WSR is the ratio of the mass of solubilized organic compounds per unit of surfactant mass in micellar solution. MSR is defined as the moles of solubilized organic compounds per mole of surfactant in micellar solution [26,27]. Sharmin et al. calculated the MSR for perchloroethylene with Triton X-100 as a surfactant obtaining a value of $2.1 \mathrm{~mol}_{j} \cdot \mathrm{mol}^{-1}{ }_{\text {surf }}$ [28]. Kibbey et al. reported values of MSR in the range of 3.99-17.82 $\mathrm{mol}_{j} \cdot \mathrm{mol}^{-1}$ surf depending on the volume ratio of organic and aqueous phases using tetrachloroethylene and Tergitol NP15 as surfactants [29]. Zimmerman et al. reported apparent MSR values for different compounds (trichloroethylene, tetrachloroethylene, chlorobenzene, 1,2-dichlorobenzene) and by using different nonionic surfactants in the range of 0.5 to $4 \mathrm{~mol}_{j} \cdot \mathrm{mol}^{-1}{ }_{\text {surf }}$ [30]. Kang et al. also provided values of MSR for Tween 80, 40, and 20 using trichloroethylene and tetrachloroethylene as organic compounds. They found values

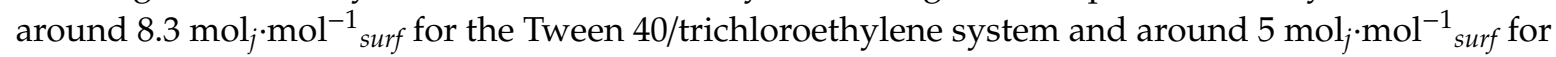
Tween 80/tetrachloroethylene [31].

The extent of micellar solubilization depends on many factors (surfactant structure, aggregation number, micelle geometry, hydrophilic/lipophilic balance (HLB), ionic strength, temperature, and the size and chemistry of the solute) [32]. The HLB value is one of the most investigated parameters, but this number cannot confirm the required concentration of the emulsifying agent or the stability of the emulsions [23]. Moreover, there is a lack of studies carried out using real mixtures of organic compounds [33].

Additionally, due to the amphiphilic nature of the surfactant molecule, when a surfactant solution is in contact with an organic phase (such as the DNAPL), the partition of the surfactant between aqueous and organic phases has to be considered to determine the remaining amount of surfactant in solution $[30,31]$. The partition of surfactant between phases can reduce their active concentrations in an aqueous phase for the solubilization and mobilization of pollutants [31,34], affecting the effectiveness of the remediation treatment. The partition of the surfactant between both phases has been scarcely studied in literature [31,32,35]. Moreover, in these studies, the organic phase, as a DNAPL model, was composed of a single compound (chlorobenzene, 1,2-dichlorobenzene, 1,1,2-trichloroethane [36], perchloroethylene [28], tetrachloroethylene [29,30,36], dichloromethane, chloroform [30]). Only Yang et al. [37] studied binary mixtures of trichloroethylene and perchloroethylene. From literature results, it seems that nonionic surfactants present a higher affinity for the organic phases than anionic surfactants [31].

Correlations between the partition of a surfactant in both phases and the properties of that surfactant have been investigated in the literature. Catanoiu et al. [38] used three commercial nonionic surfactants (polyoxyethylene alkyl ethers, alkyl dimethyl phosphine oxides, and alkyl glycosides) with 
different water-in-alkane systems. They found that the affinity of the surfactant for the organic phase increases by increasing the surfactant alkyl chain length. Cowell et al. [36] studied the partitioning of ethoxylated nonionic surfactants in pure organic compounds (chlorobenzene, 1,2-dichlorobenzene, tetrachloroethylene, 1,1,2-trichloroethane), reporting that the concentration of the surfactant in the organic phase decreases when the polarity of this organic phase increases. This conclusion was also supported by the results of Kang et al., who studied the partitioning of different nonionic surfactants using pure compounds as an organic phase [31]. As commented before, the partitioning of surfactants between organic and aqueous phases using real DNAPL mixtures is not available in literature.

The $\mathrm{pH}$ effect on the partitioning equilibria has been scarcely studied, although it is proved that alkaline conditions can produce dehydrochlorination reactions of pesticides as lindane $[39,40]$ or alkaline hydrolysis of organophosphorus pesticides, such as parathion and methyl parathion [33], generating less toxic products. Muff et al. [33] studied the solubilization of a NAPL compounded of two organophosphorus pesticides $(50 \% \mathrm{w}: \mathrm{w})$ in a polluted soil under strong alkaline conditions using several surfactants.

In this research, the partitioning equilibrium of surfactants and organic compounds between the organic and the aqueous phases has been studied using two different DNAPL samples. These DNAPLs were extracted from Sardas (S) and Bailin (B) landfills, caused by the dumping of liquid wastes from lindane production [7] containing up to 28 different chlorinated organic compounds [6]. The residues of the lindane produced by the company INQUINOSA were first disposed in the Sardas landfill, and later, in the Bailin landfill (Sabiñanigo, Spain), both unlined. The liquid waste dumped (DNAPL) had migrated by density forces through the subsoil in both landfills (Sardas and Bailin), with the corresponding conceptual models available in the literature [7,41]. The detection of this liquid waste was found at very variable depths, from $40 \mathrm{~m}$ deep under the ground level to the surface [7]. The groundwater in both landfills is connected to the Gallego river, and the solubilization of DNAPL in groundwater is a significant risk for the nearby river and reservoir [7,41].

To the best of our knowledge, the works available in literature studying these partitioning equilibria use pure organic compounds $[30,31,36]$ or binary mixtures [42] at neutral $\mathrm{pH}$.

In addition, the effect of alkaline $\mathrm{pH}$ on partition equilibria (scarcely studied in literature) is analyzed since strong alkaline conditions can be used in a real treatment to promote the dehydrochlorination reactions of the most toxic COCs in DNAPLs.

Biodegradable nonionic and ionic surfactants have been selected, while good biodegradability is required for the application of a surfactant in aquifer remediation. Tween 80 and Span 80 or their mixtures have been proved to be readily biodegradable $[43,44]$ and will be studied in this research. A commercial surfactant, E-Mulse ${ }^{\circledR}$ 3, used in the remediation of sites with DNAPLs at full scale [22] has also been tested. Finally, sodium dodecyl sulfate (SDS), a widely used surfactant in soil remediation studies [45], has been selected as an anionic surfactant.

\section{Materials and Methods}

\subsection{Chemicals}

Three nonionic surfactants and an ionic surfactant were used. The nonionic surfactants tested were E-Mulse ${ }^{\circledR} 3$ (E3), Tween ${ }^{\circledR} 80$ (T80), and a mixture of Tween ${ }^{\circledR} 80$ at $35 \%$ and Span ${ }^{\circledR} 80$ at $65 \%$ (TS80). This mixture was tested in a previous laboratory study carried out by the Aragon Government using a DNAPL from the Sardas landfill (Sabiñanigo, Spain) [46]. Moreover, the three nonionic surfactants were biodegradable and non-toxic.

The anionic surfactant selected was sodium dodecyl sulfate (SDS), which is also typically used in soil washing. The identification of surfactants and their main chemical properties are shown in the Supplementary Material, Table S1. As can be seen, a nonionic surfactant presents a lower micellar concentration (CMC) than SDS. 
Two different DNAPL samples obtained from the Sabiñánigo landfills and provided by the company EMGRISA and the Aragon Government were used. One DNAPL sample was obtained from the Sardas landfill (S) and the other sample from the Bailin landfill (B). The composition (molar fraction) of DNAPLs used in this research is summarized in Table S2 of the Supplementary Information. In this table, the average molecular weight $\mathrm{MW}_{\mathrm{DNAPL}}$ for both DNAPLs is also included (232 $\mathrm{mg} \cdot \mathrm{mmol}^{-1}$ and $191 \mathrm{mg} \cdot \mathrm{mmol}^{-1}$ for DNAPL: B and S, respectively). As can be seen, both DNAPLs contain up to 28 chlorinated organic compounds (COCs): chlorobenzene (CB) and different isomers of dichlorobenzene (DCBs), trichlorobemzenes (TCBs), tetrachlorobenzene (TetraCBs), pentachlorocyclohexene (PentaCXs), hexachlorocyclohexanes (HCHs), and heptachlorocyclohexanes (HeptaCHs). Compound distribution is quite similar to that mentioned in previous research [6]. These COCs represent more than $95 \%$ of the DNAPL mass.

\subsection{Solubility Experiments}

Solubility experiments were conducted in sealed GC $20 \mathrm{~mL}$ glass vials without headspace, closed with PTFE caps. A mass of $0.4 \mathrm{~g}$ of each organic phase, DNAPL: B, and DNAPL: $\mathrm{S}$, was added to $19.6 \mathrm{~g}$ of the aqueous phase containing the surfactant (surfactant concentration ranging from 0 to $17 \mathrm{~g} \mathrm{~L}^{-1}$ ). These experiments were carried out on both neutral and alkaline $\mathrm{pH}(\mathrm{pH}>12)$. An alkaline $\mathrm{pH}$ was achieved by adding $\mathrm{NaOH}$ up to $7 \mathrm{~g} \mathrm{~L}^{-1}$ in the aqueous phase containing the surfactant. Table $\mathrm{S} 3$ provides a summary of the conditions of the experiments carried out. Six identical vials, which were sacrificed at different times of agitation, were prepared for each test.

The biphasic mixture (organic and aqueous) was agitated using a magnetic stirrer under room conditions for $5 \mathrm{~h}$ at room-controlled temperature $\left(\mathrm{T}=22 \pm 2{ }^{\circ} \mathrm{C}\right)$. Then, the agitation was stopped and different vials were sacrificed at $0.5,1,3,24,48$, and $75 \mathrm{~h}$ to analyze the aqueous emulsion. The experiments were carried in triplicate. The differences were lower than $10 \%$.

\subsection{Analytical Methods}

The qualitative identification of dissolved COCs in the aqueous phase was carried out using a gas chromatograph (GC) (Agilent $6890 \mathrm{~N}$, Sante Clara, CA, USA) along with a mass selective detector (Agilent MSD 5975B, Sante Clara, CA, USA). The quantification of COCs in the emulsion was carried out using a GC (Agilent 6890, Sante Clara, CA, USA) with both a flame ionization detector (FID) (Sante Clara, CA, USA) and an electron capture detector (ECD) (Sante Clara, CA, USA), simultaneously. The GC methods are described elsewhere [6]. The aqueous phase samples containing surfactants were previously diluted 1:10 with methanol to analyze the COCs.

The total organic carbon (TOC) of the supernatant (aqueous phase with the surfactant and solubilized COCs) was measured once the equilibrium was reached between phases (COC concentration in emulsion did not change over time). A Shimadzu TOC-V (Kyoto, Japan) analyzer was used. The concentration of nonionic surfactant under equilibrium conditions was determined from the TOC value and sum of COCs in the emulsion.

Ionic surfactant (SDS) concentration in aqueous phases was quantified by measuring sulfate anions in an aqueous solution using IC (Metrohm 761 Compact IC, Herisau, Switzerland). The column used as a stationary phase was Metrosep A SUPP5 5-250 ( $250 \mathrm{~mm}$ long, $4 \mathrm{~mm}$ wide) (Gallen, Switzerland), and the mobile phase used was an aqueous solution of $\mathrm{Na}_{2} \mathrm{CO}_{3}\left(3.2 \mathrm{mmol} \cdot \mathrm{L}^{-1}\right)$ and $\mathrm{NaHCO}_{3}\left(1 \mathrm{mmol} \cdot \mathrm{L}^{-1}\right)$.

To ensure that $\mathrm{pH}$ conditions were maintained throughout the entire experiment, the $\mathrm{pH}$ was also analyzed in the samples using a $914 \mathrm{pH} /$ Conductometer (Metrohm, Herisau, Switzerland).

\section{Results and Discussions}

\subsection{Partitioning of a Surfactant under Equilibrium Conditions}

When equilibrium was reached, the concentration of surfactant absorbed in the organic phase $\left(C_{s u r f, O R G}\right)_{e q}$ and the aqueous phase $\left(C_{s u r f, A Q}\right)_{e q}$ were calculated from the surfactant mass balance as 
shown in the Supplementary Information. The mass of organic phase not dissolved at equilibrium conditions $\left(w_{\text {org }}\right)_{E Q}$ was obtained from the DNAPL mass balance, as shown in equation (S1) to (S3) in the Supplementary Information. It was found that equilibrium conditions for the concentration of COCs in solution were obtained in under $24 \mathrm{~h}$, remaining almost constant in the range of the $24-75 \mathrm{~h}$ time interval studied here.

The partition of surfactant between organic and aqueous phases for both DNAPLs (B and S) under equilibrium conditions is plotted at $\mathrm{pH}=7$ in Figure $1 \mathrm{a}, \mathrm{b}$ and at $\mathrm{pH}>12$ in Figure 1c,d. (Data obtained after $48 \mathrm{~h}$ are used).

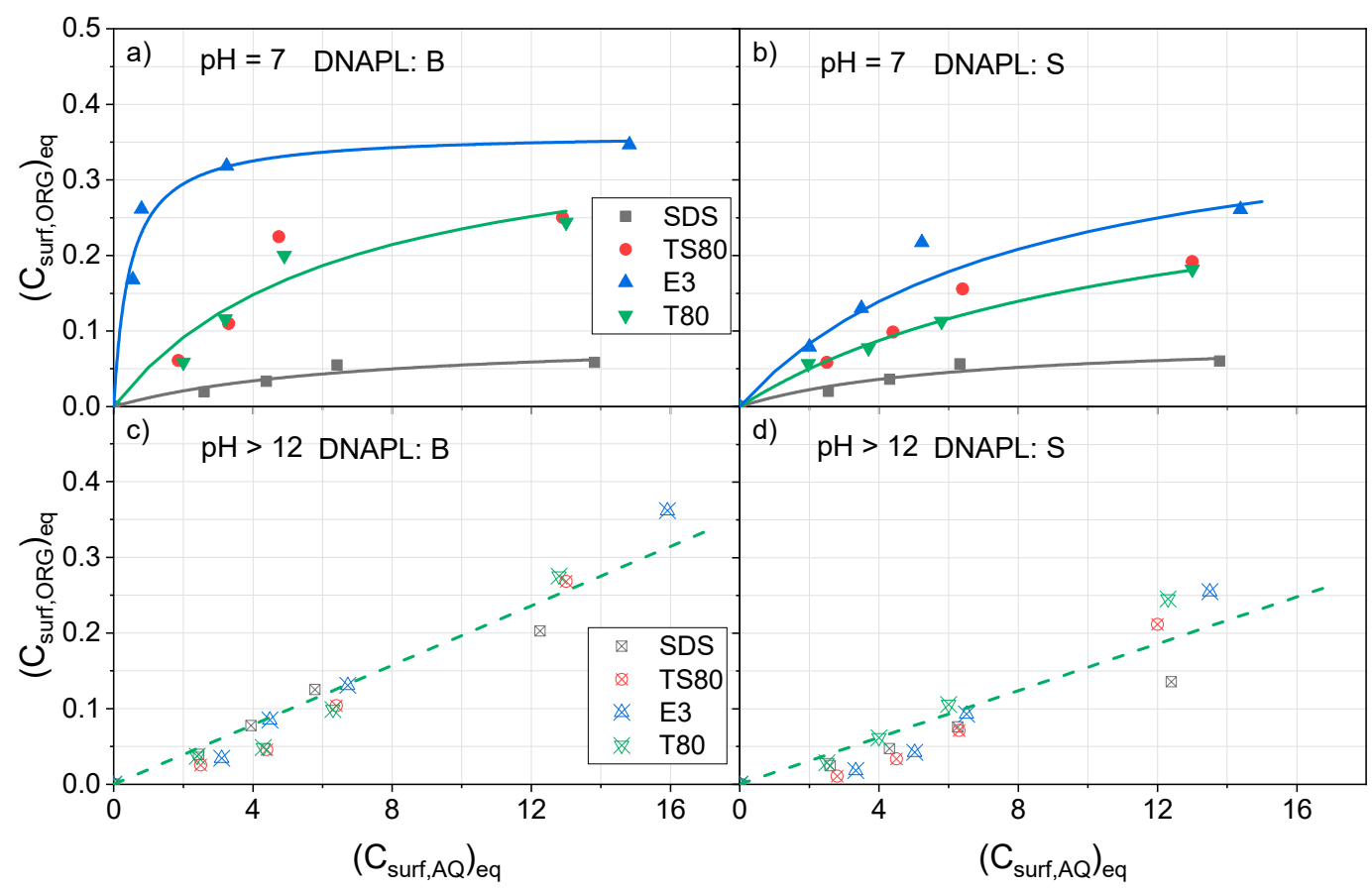

Figure 1. Partitioning of surfactants in organic-aqueous phases at (a) $\mathrm{pH}=7$, dense nonaqueous phase liquid (DNAPL): Bailin (B), (b) pH = 7 DNAPL: Sardas (S) (c) pH > 12 DNAPL: B (d) pH > 12 DNAPL: S $\left(C_{\text {surf }, \text { ORG }}\right)_{e q}$ in $\mathrm{g}_{\text {surf }} \mathrm{g}_{\mathrm{ORG}}{ }^{-1}$ and $\left(C_{\text {surf }, A Q}\right)_{e q}$, in $\mathrm{g}_{\text {surf }} \mathrm{L}^{-1}$. Experimental values as symbols and predicted values by Equation (1) or Equation (2) with parameters in Table 1 as lines.

Table 1. Parameters estimated by fitting experimental data in Figure $1 \mathrm{a}, \mathrm{b}$ to the Langmuir isotherm in Equation (1) and experimental data in Figure 1c,d to the linear partitioning model in Equation (2). The statistical significance of parameters is summarized in Table S4.

\begin{tabular}{|c|c|c|c|c|c|c|}
\hline \multirow[b]{3}{*}{ Surf. } & \multicolumn{3}{|c|}{$\mathrm{pH}=7$} & \multicolumn{3}{|c|}{$\mathrm{pH}=7$} \\
\hline & \multicolumn{3}{|c|}{ DNAPL: B } & \multicolumn{3}{|c|}{ DNAPL: $\mathrm{S}$} \\
\hline & $\begin{array}{c}C_{s, O R G} \\
\mathrm{~g}_{s u r f} \mathrm{~g}^{-1} \text { ORG }\end{array}$ & $\begin{array}{c}K_{S} \\
\mathrm{~L} \cdot \mathrm{g}^{-1} \text { surf }\end{array}$ & $\begin{array}{c}K_{L} \\
\mathrm{~g}_{\text {surf,ORG }} \cdot \mathrm{L} \cdot \mathrm{g}^{-1}{ }_{\text {surf }} \cdot \mathrm{g}^{-1} \text { ORG }\end{array}$ & $\begin{array}{c}C_{S, \text { ORG }} \\
\mathrm{g}_{\text {surf }} \cdot \mathrm{g}^{-1} \text { ORG }\end{array}$ & $\begin{array}{c}K_{S} \\
\mathrm{~L} \cdot \mathrm{g}^{-1} \text { surf }\end{array}$ & $\begin{array}{c}K_{L} \\
\mathrm{~g}_{\text {surf,ORG }} \cdot \mathrm{L} \cdot \mathrm{g}^{-1}{ }_{\text {surf }} \cdot \mathrm{g}^{-1} \text { ORG }\end{array}$ \\
\hline SDS & 0.093 & 0.143 & 0.013 & 0.093 & 0.159 & 0.015 \\
\hline $\begin{array}{c}\text { T80 and } \\
\text { TS80 }\end{array}$ & 0.387 & 0.155 & 0.059 & 0.354 & 0.097 & 0.034 \\
\hline \multirow[t]{3}{*}{ E3 } & 0.362 & 2.179 & 0.789 & 0.415 & 0.126 & 0.052 \\
\hline & \multicolumn{3}{|c|}{$\mathrm{pH}>12$} & \multicolumn{3}{|c|}{$\mathrm{pH}>12$} \\
\hline & $\begin{array}{c}C_{s, O R G} \\
\mathrm{~g}_{\text {surf }} \cdot \mathrm{g}^{-1} \text { ORG }\end{array}$ & $\begin{array}{c}K_{S} \\
\mathrm{~L} \cdot \mathrm{g}^{-1}{ }_{\text {surf }}\end{array}$ & $\begin{array}{c}K_{L} \\
\mathrm{~g}_{\text {surf,ORG }} \cdot \mathrm{L} \cdot \mathrm{g}^{-1}{ }_{\text {surf }} \cdot \mathrm{g}^{-1} \text { ORG }\end{array}$ & $\begin{array}{c}C_{s, \text { ORG }} \\
\mathrm{g}_{\text {surf }} \cdot \mathrm{g}^{-1} \text { ORG }\end{array}$ & $\begin{array}{c}K_{S} \\
\mathrm{~L} \cdot \mathrm{g}^{-1} \text { surf }\end{array}$ & $\begin{array}{c}K_{L} \\
\mathrm{~g}_{\text {surf, ORG }} \cdot \mathrm{L} \cdot \mathrm{g}^{-1} \text { surf } \cdot \mathrm{g}^{-1} \text { ORG }\end{array}$ \\
\hline All & & & 0.020 & & & 0.016 \\
\hline
\end{tabular}

As can be seen in Figure 1a, the concentration of E3 in organic phase B at neutral pH reaches an asymptotic value, about $0.35 \mathrm{~g}_{\text {surf }} \cdot \mathrm{g}^{-1} \mathrm{ORG}$, when surfactant concentration in the aqueous phase is higher than $4 \mathrm{~g} \cdot \mathrm{L}^{-1}$. Lower partition ratios between the organic and aqueous phases were obtained using T80, TS80, and SDS. The partition ratios of T80 and TS80 were similar. Meanwhile, the lowest 
values were found with SDS. Moreover, asymptotic values are not achieved with T80, TS80, and SDS for concentrations lower than $15 \mathrm{~g} \cdot \mathrm{L}^{-1}$. Differences in the partition behavior of the surfactant tested at neutral $\mathrm{pH}$ indicate a higher affinity of $\mathrm{E} 3$ for organic phase $\mathrm{B}$.

By comparing the results in Figure 1a,b, it can be deduced that surfactants have a lower affinity for DNAPL: $S$ than for DNAPL: B. The highest discrepancies are found for the nonionic surfactant. This fact can be explained by differences in the composition of each organic phase B and S. It has been described in literature that the lower the polarity of the organic compounds, the higher the absorption of the nonionic surfactant in the organic phase [36]. As can be seen in Table S2, molar fractions of PentaCX, HexaCX, HCH, and HeptaCH isomers are higher in DNAPL: B than in DNAPL: S. On the contrary, molar fractions of DCB, TCB, and TetraCB isomers are higher in DNAPL: B. Therefore, the polarity of DNAPL: $B$ is expected to be higher and, consequently, the affinity of the nonionic surfactant lower [36].

Results obtained at $\mathrm{pH}>12$ are shown in Figure 1c,d for DNAPL: B and S, respectively. As can be seen, the partition behavior of the four surfactants is similar for each DNAPL, and the differences found can be due to experimental error. Moreover, almost linear relationships are found between surfactant concentration in the organic and aqueous phases, and asymptotic values are not noticed in the concentration range studied. Surfactant concentration in the organic phase is slightly lower in DNAPL: $S$ than in DNAPL: B. It can be generally noted that the affinity of the nonionic surfactants for the organic phase is more inferior in alkaline conditions than at neutral $\mathrm{pH}$, at least when the surfactant concentration in the aqueous phase is lower than $15 \mathrm{~g} \cdot \mathrm{L}^{-1}$. On the contrary, the higher the $\mathrm{pH}$, the higher the affinity of SDS for the organic phase. These effects can be explained, taking into account that the presence of electrolytes in the aqueous phase can modify the partition of the surfactant [34]. Moreover, alkaline conditions can alter both the polarity of the DNAPL surface and the surfactant micelles, thus affecting the surfactant partition.

To model the partition of surfactant between organic and aqueous phases, some authors $[30,31,37]$ have used Langmuir isotherms, as shown in Equation (1).

$$
\left(C_{\text {surf }, \text { ORG }}\right)_{e q}=\left[C_{s, O R G} \cdot K_{s} \cdot\left(C_{s u r f, A Q}\right)_{e q}\right] /\left(1+K s \cdot\left(C_{s u r f, A Q}\right)_{e q}\right),
$$

where $C_{s, O R G}$ is the saturation concentration of surfactant in the organic phase, in $\mathrm{g}_{\text {surf }} \mathrm{g}^{-1}$ ORG , and $K_{S}$ the constant affinity of the surfactant for the organic phase, in $\mathrm{L}^{-1}{ }^{-1}$ surf.

The experimental values shown in Figure 1a,b were fitted to Equation (1) by using non-linear regression, and the corresponding parameters calculated are shown in Table 1. Taking into account that similar behavior was obtained with surfactants T80 and TS80 (Figure 1a,b) and the differences can be explained by uncertainty in the experimental data, the results obtained with both surfactants were joined together. The statistical significance of parameters is summarized in Table S4. On the other hand, in Figure $1 c, d$, the partition of the surfactants between the organic and the aqueous phase presents a linear trend at $\mathrm{pH}>12$ and the concentrations applied. In this case, the expression in Equation (2) was proposed:

$$
\left(C_{\text {surf }, \text { ORG }}\right)_{e q}=K_{L} \cdot\left(C_{\text {surf }, A Q}\right)_{e q} .
$$

$K_{L}$ is the linear partitioning parameter [31] in $\mathrm{g}_{\text {surf }, \mathrm{ORG}} \cdot \mathrm{L}^{\mathrm{g}} \mathrm{g}^{-1}$ surf $\cdot \mathrm{g}^{-1} \mathrm{ORG}$. Equation (1) can be simplified using Equation (2) for small values of $K_{L}$. The latter parameter is the product of $C_{s, O R G}$ by $K_{s}$ in Equation (2).

The experimental data obtained in alkaline conditions was fitted to Equation (2) using linear regression and a $K_{L}$ parameter was estimated. Since the four surfactants had a similar partitioning behavior under alkaline conditions, the experimental data was fitted together. A unique value of $K_{L}$ was obtained for each DNAPL, which is also shown in Table 1. As can be seen in Table 1, slightly lower values of $K_{L}$ were obtained with DNAPL: S, indicating that a lower affinity of this organic phase $S$ for the surfactant is also found at an alkaline $\mathrm{pH}$.

The corresponding values of $K_{L}$ at $\mathrm{pH}=7$ are also shown in Table 1 . As can be seen, higher $K_{L}$ values for nonionic surfactants are obtained at a neutral $\mathrm{pH}$, for both DANPLs B and S. On the contrary, 
higher $K_{L}$ values are obtained using the anionic surfactant SDS under alkaline conditions. In all cases, it is confirmed that $\mathrm{pH}$ has a strong influence on the affinity of the surfactant for the organic phases.

\subsection{Solubilization of COCs}

The solubilization experiments carried out are summarized in Table S3. In Figures S1-S5 of the Supplementary Material, some photos of the emulsions before agitation (up), after stirring (centrum), and $75 \mathrm{~h}$ after the agitation stopped are shown. As can be seen, the emulsions had a light brown appearance after agitation, being darker in the experiments with DNAPL: S. The brown color settled overtime after the agitation stopped, due to the presence of some clay interbedded in both DNAPL: B and S (more evident in DNAPL: S). As the total amount of COCs quantified represents more than 95\% of the mass in both DNAPLs, the percentage of clay is lower than $5 \%$ in all cases.

As explained in the experimental part, for each experiment in Table S3, a vial was sacrificed at different settling times, and the amount of COCs in the aqueous phase was measured. The profiles of COCs in solution with the settling time is shown in Figure 2. As can be seen, although the clay gradually precipitated during the settling of the COC, the concentration in the aqueous phase remained constant $24 \mathrm{~h}$ after the agitation had stopped and the equilibrium was achieved.

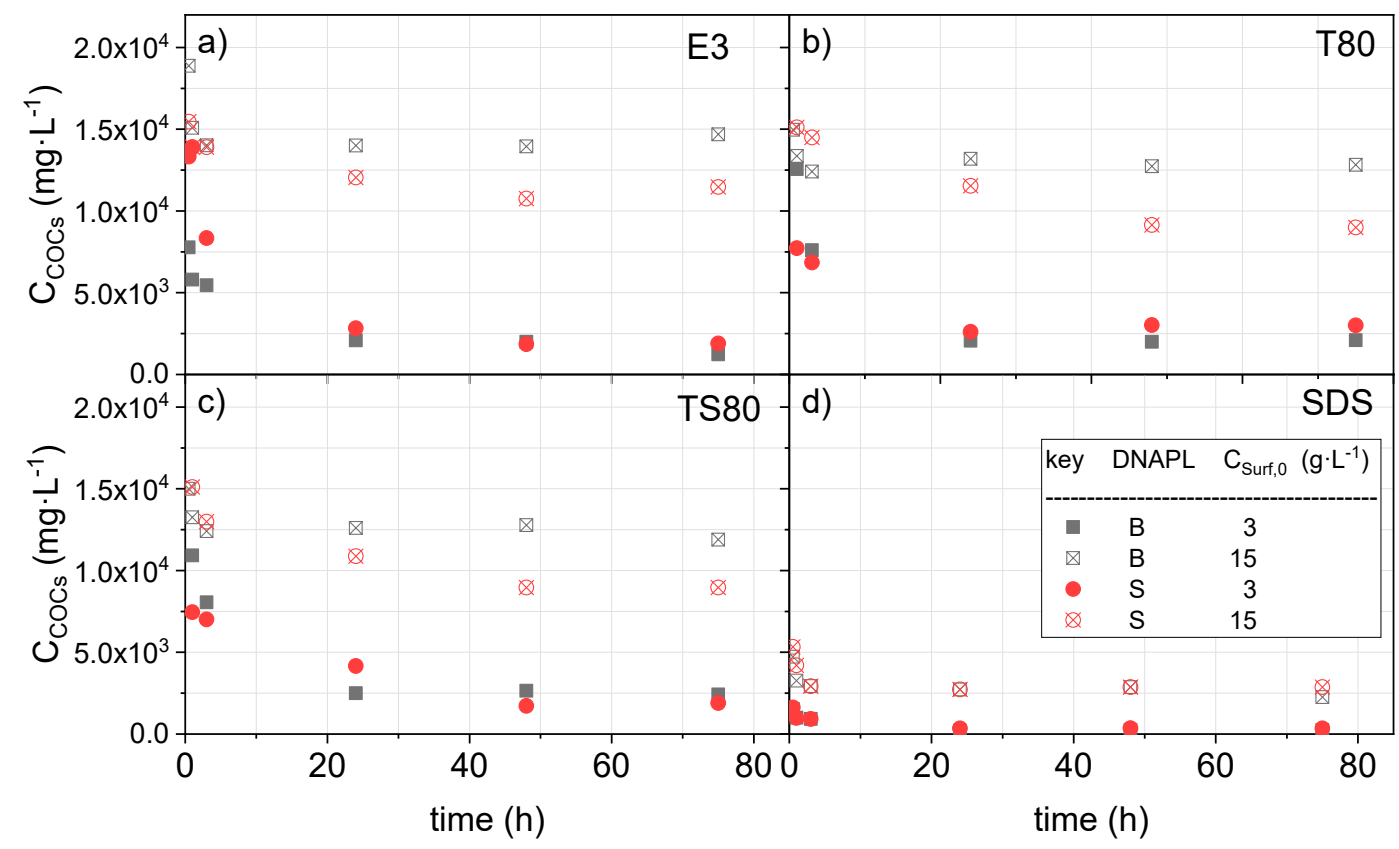

Figure 2. Evolution of chlorinated organic compounds (COCs) concentration in aqueous phase with (a) E3 at 3 and $15 \mathrm{~g} \cdot \mathrm{L}^{-1}$; (b) T80 at 3 and $15 \mathrm{~g} \cdot \mathrm{L}^{-1}$; (c) TS80 at 3 and $15 \mathrm{~g} \cdot \mathrm{L}^{-1}$; (d) sodium dodecyl sulfate (SDS) at 3 and $15 \mathrm{~g} \cdot \mathrm{L}^{-1}$ and $\mathrm{pH}=7$.

\subsubsection{Distribution of Solubilized COCs}

As the DNAPL samples used in this research are a complex mixture of COCs, a study has been conducted to see if the surfactants selectively dissolve some compounds in the mixture. The molar distribution of COCs in the DNAPL sample is summarized in Table S2. The percentage of each solubilized COC in the aqueous phase is calculated as follows:

$$
y(\% \text { mole })=100 \cdot\left[\left(C_{j, A Q} / M W_{j}\right) /\left(\sum C_{j, A Q} / M W_{j}\right)\right]_{e q},
$$

where $C_{j, A Q}$ is the concentration of $j$ in the aqueous phase, $\mathrm{mg} \cdot \mathrm{L}^{-1}$ and $M W_{j}$ are the molecular weight of $j$. In $\mathrm{mg} \cdot \mathrm{mmol}^{-1}, \mathrm{COC}$ isomers have been lumped together, so $j$ refers to $\mathrm{CB}$, the sum of DCBs, TCBs, TetraCBs, PCB, PentaCXs, HexaCXs, HCHs, and HeptaCHs isomers. 
The molar percentages of solubilized COCs (calculated by Equation (3)) under equilibrium conditions at two different initial surfactant concentrations $\left(3 \mathrm{~g} \cdot \mathrm{L}^{-1}\right.$ and $\left.15 \mathrm{~g} \cdot \mathrm{L}^{-1}\right)$ at neutral $\mathrm{pH}$ are shown in Figures 3 and 4, for DNAPL: B and S, respectively. As can be seen, the higher the surfactant concentration, the higher the sum of solubilized COCs.

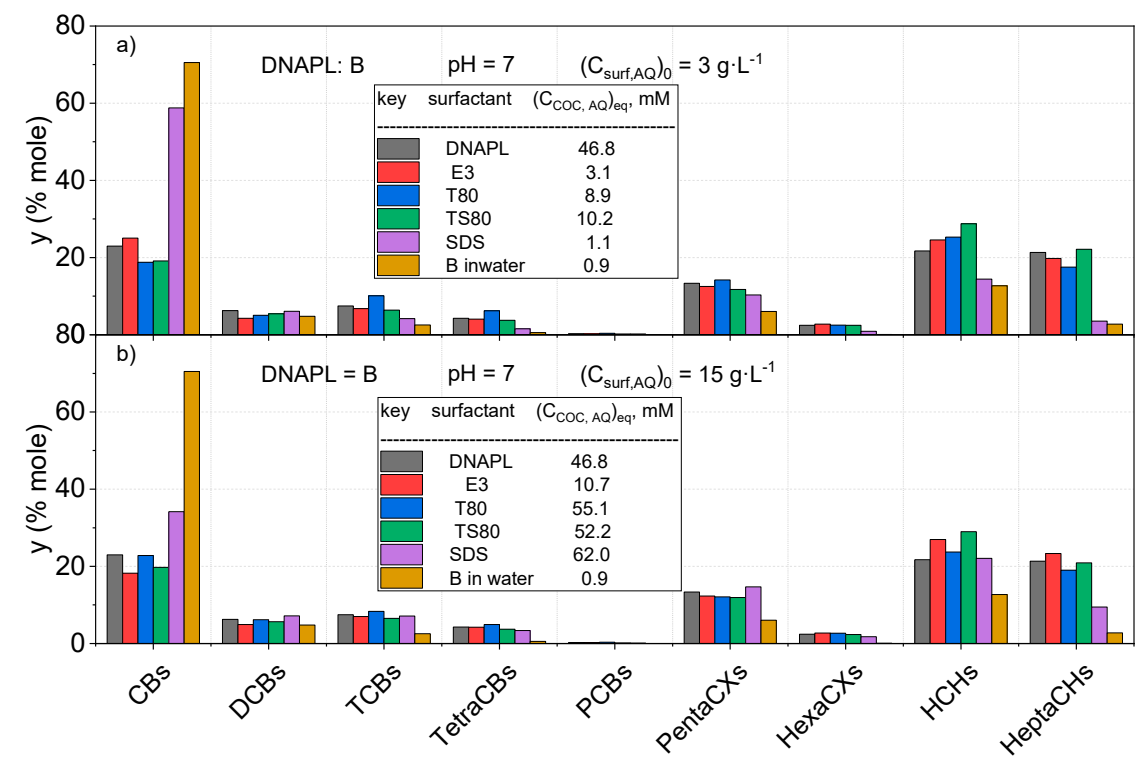

Figure 3. Molar distribution (\%) of COCs in the initial DNAPL: B as a sum of isomers and COC distribution in the aqueous phase using an initial surfactant concentration of $(\mathbf{a})\left(C_{\text {surf }, A Q}\right)_{0}=3 \mathrm{~g} \cdot \mathrm{L}^{-1}$ (b) $\left(C_{\text {surf }, A Q}\right)_{0}=15 \mathrm{~g} \cdot \mathrm{L}^{-1}$ at $\mathrm{pH}=7$. The distribution of solubilized COCs in the aqueous phase saturated in DNAPL (without surfactant) is given as B in water.

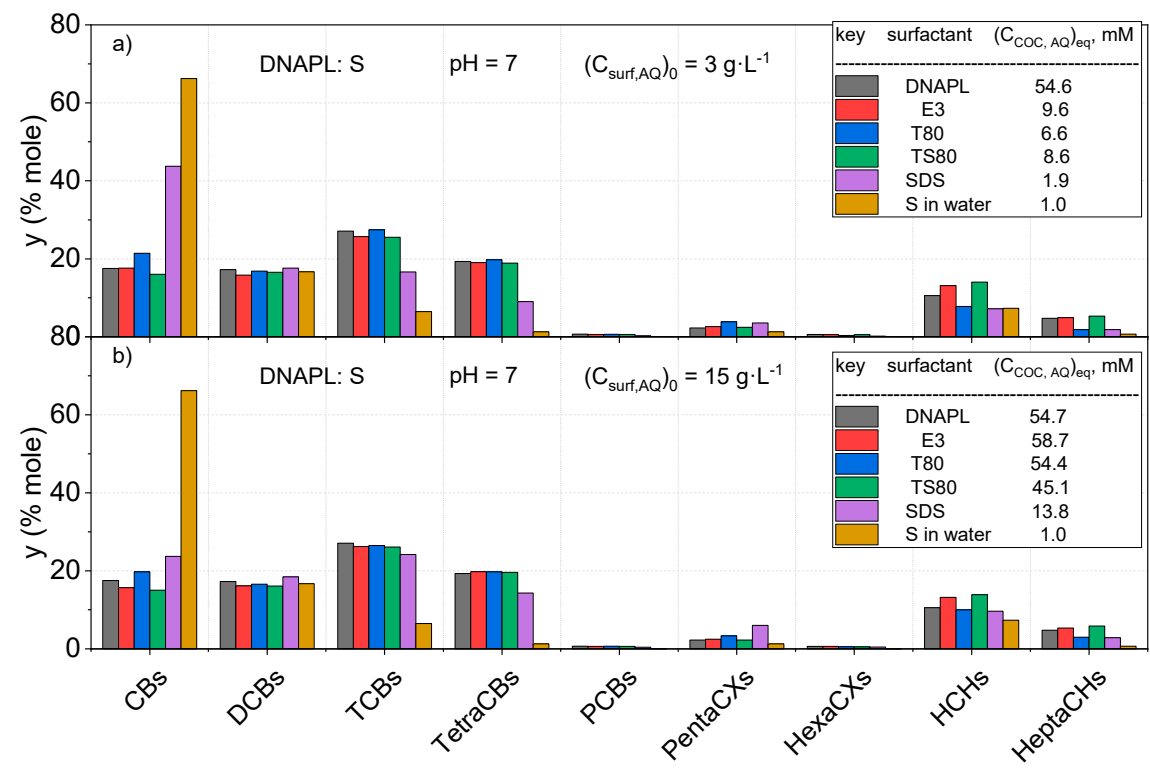

Figure 4. Molar distribution (\%) of COCs in the initial DNAPL: S as the sum of isomers and COC distribution in the aqueous phase using an initial surfactant concentration of $(\mathbf{a})\left(C_{\text {surf, } A Q}\right)_{0}=3 \mathrm{~g} \cdot \mathrm{L}^{-1}$ (b) $\left(\mathrm{C}_{\text {surf,AQ }}\right)_{0}=15 \mathrm{~g} \cdot \mathrm{L}^{-1}$ at $\mathrm{pH}=7$. The distribution of solubilized COCs in water is also provided as DNAPL saturated in water.

Moreover, the distribution of COCs in the aqueous phase without surfactant and DNAPL are also included. As can be seen, the distribution of COCs solubilized by nonionic surfactants is quite similar to the initial distribution of COCs in the organic phase (the latter is shown in Table S2), 
for both DNAPL: B (Figure 3) and S (Figure 4). Differences are lower than 15\%, regardless of the initial surfactant concentration in the aqueous phase. This fact can be explained assuming that the organic phase is trapped in the micellar cores and the aqueous phase is emulsified. Therefore, for the nonionic surfactants tested, the complex mixture forming the DNAPL can be joined together as a single compound.

On the contrary, the solubilization of COCs without surfactant presents a different distribution, following the partitioning of these compounds in the aqueous phase reported elsewhere [6,39]. The distribution of COCs in the aqueous phase without surfactants is quite different from their distribution in the organic phase, where chlorobenzene is the most abundant dissolved COC.

On the other hand, COC distribution obtained with SDS at a low surfactant concentration is more similar to that found in the aqueous phase without surfactant, as can be seen in Figures 3 and 4 . However, the higher the SDS concentration, the more similar the distribution of dissolved COCs to that found in the organic phase, although some selectivity is still noticed.

The total COCs concentrations in the aqueous phase from the solubility experiments are shown in the legends of Figures 3 and 4 .

The effect of the addition of alkali on solubilized COC distribution in the presence of surfactants under equilibrium conditions was analyzed. COC distribution in the aqueous phase obtained at initial surfactant concentrations of 3 and $15 \mathrm{~g} \cdot \mathrm{L}^{-1}$ is summarized in Figures S6 and S7 for DNAPL: B and $\mathrm{S}$, respectively. For comparison purposes, $\mathrm{COC}$ distribution at neutral $\mathrm{pH}$ and the total moles of dissolved COCs at neutral and alkaline $\mathrm{pHs}$ are also shown in these figures. The concentration of COCs in the aqueous phase is also summarized in the captions of the figures mentioned above.

As can be seen in Figures S6 and S7, for a given surfactant concentration, the total moles of dissolved COCs are similar at both $\mathrm{pHs}$, but their distribution changes. PentaCX, HexaCX, $\mathrm{HCH}$, and $\mathrm{HeptaCH}$ isomers are not detected in the aqueous emulsions under alkaline conditions while TCBs and TetraCB molar percentages have remarkably increased under these conditions. It has been reported elsewhere [39] that under alkali conditions, $\mathrm{HCH}$ and PentaCX isomers in the aqueous phase produce TCB and HeptaCHs compounds and HexaCXs are transformed into TetraCBs. Dehydrochlorination reactions and selectivity concerning TCB and TetraCB isomers obtained are shown in Figures $\mathrm{S} 8$ and S9, following that reported by Lorenzo et al. [39]. Therefore, the alkaline conditions produced the transformation of some compounds in a solubilized fraction of DNAPL inside the micelles generated by the surfactant due to alkaline conditions; however, similar molar total concentration of COCs in solution is obtained at neutral and alkaline pHs. Moreover, the TCBs and TetraCBs produced under alkaline conditions are less toxic than the precursors' organic compounds ( $\mathrm{HCHs}$ and HeptaCHs, respectively) [47-50].

\subsubsection{Partition Equilibria of Solubilized COCs}

From the results shown in Table S5, it is clear that the concentration of solubilized COCs depends on the concentration of the surfactant added. In addition, it has been found that for a nonionic surfactant, the complex mixture of compounds in DNAPL can be joined together as a single solubilized compound.

The partition of COCs and equilibrium conditions can be modeled employing the MSR (or WSR) parameters defined in Equation (4).

$$
\begin{gathered}
M S R=\left(C_{C O C s, A Q}\right)_{e q} /\left(C_{\text {surf }, A Q} / M W_{\text {surf }}\right)_{e q} ; \\
W S R=\left(\sum C_{j, A Q}\right)_{\text {eq }} /\left(C_{\text {surf }, A Q}\right)_{\text {eq }},
\end{gathered}
$$

where $M W_{\text {surf }}$ is the molecular weight of the surfactant summarized in Table S1 (but for E3 that is unknown). The sum of COCs dissolved has been called $\mathrm{C}_{\mathrm{COCs}, \mathrm{AQ}}$, in $\mathrm{mmol} \cdot \mathrm{L}^{-1}$ defined as

$$
\left(C_{C O C s, A Q}\right)_{e q}=\sum\left(C j_{, A Q} / M W_{j}\right) .
$$


In Figure 5, the concentration of solubilized COCs calculated by (5), in $\mathrm{mmol} \cdot \mathrm{L}^{-1}$, vs. the concentration of surfactant in the aqueous phase under equilibrium conditions, calculated by Equation (S2) in the Supplementary Information), in $\mathrm{g} \mathrm{L}^{-1}$, has been plotted for both $\mathrm{pHs}$ and DNAPLs studied. As can be seen in Figure $5 a, c$ and Figure $5 b$,d, similar plots are obtained for nonionic surfactants at both pHs. It is in concordance with the assumption that the DNAPL is mobilized as an organic phase in the micellar core and the reaction of dehydrochlorination by $\mathrm{NaOH}$ takes place in this aqueous phase. Moreover, similar results are obtained regardless of the DNAPL used. The $\mathrm{pH}$ only affects the solubilization capacity of SDS. The higher the $\mathrm{pH}$, the higher the COC concentration solubilized with SDS. The explanation for this is that SDS selectively solubilized the COCs as explained in the previous section.

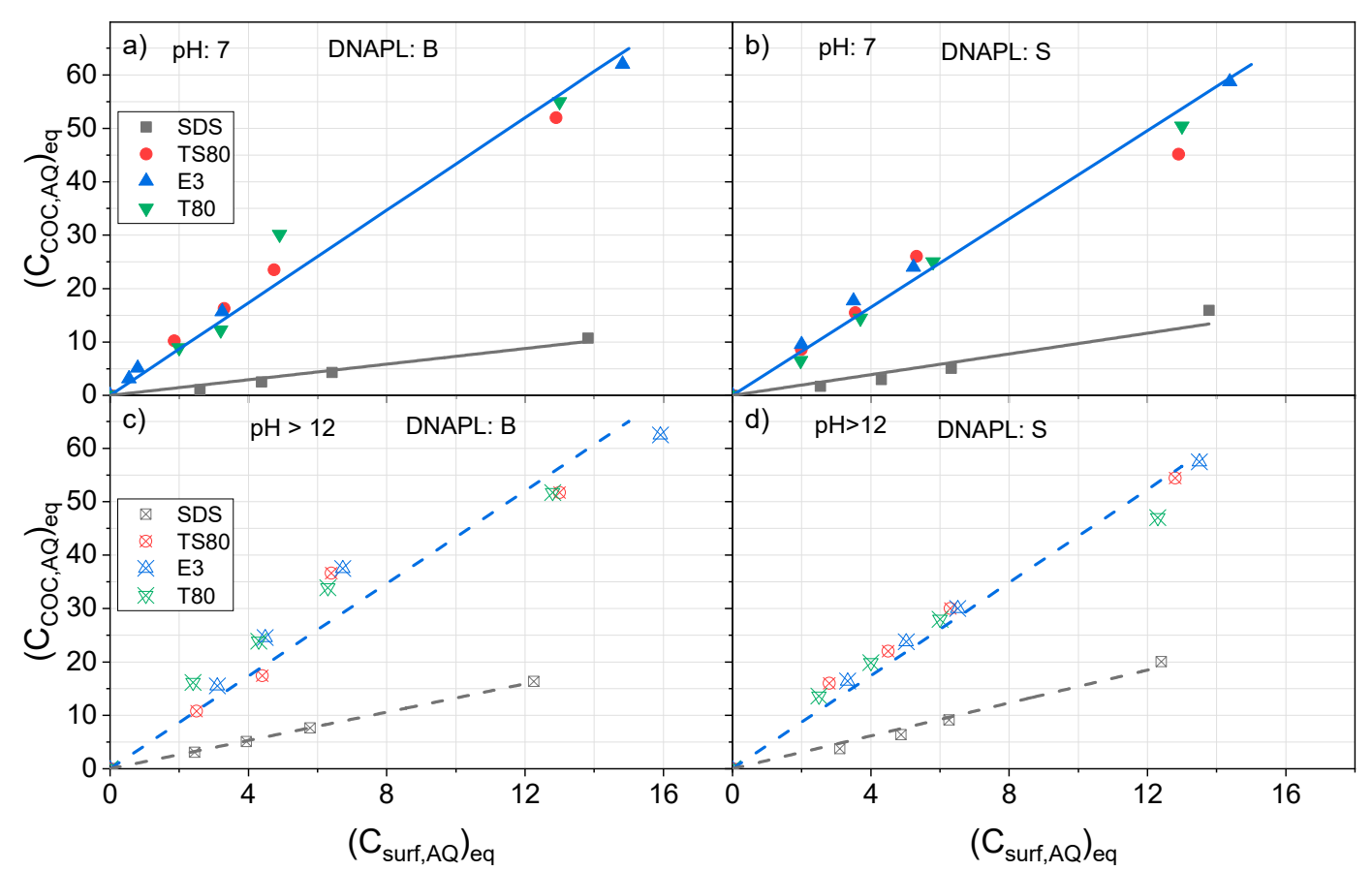

Figure 5. Aqueous phase solubility of COCs in $\mathrm{mmol}_{\mathrm{COCs}} \cdot \mathrm{L}^{-1}$ versus the concentration of surfactant in the aqueous phase in $\mathrm{g}_{\text {surf }} \mathrm{L}^{-1}$ after reaching equilibrium at $\mathrm{pH}=7$ using $(\mathbf{a}) \mathrm{B},(\mathbf{b}) \mathrm{S}$, and at $\mathrm{pH}>12$ using (c) B and (d) S.

Moreover, the higher the surfactant concentration in solution, the higher the solubilized COC concentration, meaning that an almost linear trend is found between both variables in the concentration range studied. On the other hand, lower solubilization is achieved with SDS in comparison with that obtained with nonionic surfactants, following that reported by Zhou et al. in previous research [51].

The slope of the plots in Figure 5 can be related to the MSR or MWR values obtained in Equation (4), which are summarized in Table 2. Nonionic surfactant data at both pHs and for both DNAPLs were joined together. The statistical significance of linear regression parameters obtained is summarized in Table S6.

The SMR values obtained were in line with those reported by Pei et al. for the solubilization of DCBs using different surfactants [52].

In the linear regressions, the intercept corresponds to the solubilized DNAPL in the absence of the surfactant: $0.9 \mathrm{mmol} \cdot \mathrm{L}^{-1}$ and $1.0 \mathrm{mmol} \cdot \mathrm{L}^{-1}$ for B and S, respectively, following previous results [39]. 
Table 2. Molar solubilization ratios (MSR) and mass solubilization ratio (WSR) values calculated from the slopes in Figure 5 for nonionic surfactants and SDS *.

\begin{tabular}{|c|c|c|c|}
\hline \multicolumn{4}{|c|}{ Nonionic Surfactants $\mathrm{pH}=7$ and $>12$, DNAPL: $B$ and $S$} \\
\hline & $\begin{array}{c}\text { WSR } \\
\mathrm{mg}_{\text {COCs }} \cdot \mathrm{g}^{-1}{ }_{\text {surf }}\end{array}$ & $\begin{array}{c}\mathrm{MSR}_{\mathrm{MW}} \\
\mathrm{MW}_{\mathrm{S}} \mathrm{mmol}_{\mathrm{COCS}} \cdot \mathrm{g}^{-1}{ }_{\text {surf }}\end{array}$ & $\begin{array}{c}\mathrm{MSR} \\
\mathrm{mmol}_{\mathrm{COCs}} \cdot \mathrm{mmol}^{-1}{ }_{\text {surf }}\end{array}$ \\
\hline T80 & & & 5.66 \\
\hline TS80 & 1005 & 4.33 & 3.11 \\
\hline E3 & & & - \\
\hline \multicolumn{4}{|c|}{ Anionic surfactant: SDS surfactant } \\
\hline & $\begin{array}{c}\text { WSR } \\
\mathrm{mgCOCs} \cdot \mathrm{g}^{-1} \text { surf }\end{array}$ & $\begin{array}{c}\text { MSR } \\
\mathrm{MW}_{\mathrm{S}} \mathrm{mmol}_{C O C s} \cdot \mathrm{g}^{-1}{ }_{\text {surf }}\end{array}$ & $\begin{array}{c}\text { MSR } \\
\mathrm{mmol}_{\text {COCs }} \cdot \mathrm{mmol}^{-1}{ }_{\text {surf }}\end{array}$ \\
\hline $\mathrm{pH}=7$ DNAPL: $\mathrm{B}$ & 162 & 0.7 & 0.43 \\
\hline $\mathrm{pH}=7$ DNAPL: $\mathrm{S}$ & 186 & 0.97 & 0.68 \\
\hline $\mathrm{pH}>12$ DNAPL: $\mathrm{B}$ & 307 & 1.32 & 0.8 \\
\hline $\mathrm{pH}>12$ DNAPL: $\mathrm{S}$ & 295 & 1.54 & 0.94 \\
\hline
\end{tabular}

* The statistical significance of linear regression parameters obtained is summarized in Table S6.

\section{Conclusions}

The surfactants studied here (three nonionic surfactants (E3, TS80, and T80) and one anionic surfactant (SDS)) significantly improved the solubilization of a complex mixture of chlorinated organic compounds contained in real DNAPL present in two landfills polluted with liquid organic wastes from lindane production. This improvement was remarkably greater for all nonionic surfactants tested, finding similar values of molar solubilization ratios (MSR) regardless of the $\mathrm{pH}$ used. Moreover, a significant partition of the surfactants was found between the organic and the aqueous phases. The nonionic surfactant presented a higher affinity for the organic phase at neutral $\mathrm{pH}$. For each DNAPL, the composition of COCs in the micellar core was similar to the initial composition of the organic phase for the three nonionic surfactants tested. In contrast, the anionic surfactant selectively solubilized the most polar compounds in DNAPL. Moreover, under strong alkaline conditions, dehydrochlorination of some COCs trapped in the micelles was noticed obtaining an emulsion with less toxic COC. These findings are relevant in the design of the surfactant-enhanced remediation process of the site.

Supplementary Materials: The following are available online at http://www.mdpi.com/1660-4601/17/12/4494/s1, Table S1: Surfactant tested in DNAPL solubilization and main properties. Table S2: Mole fraction of COCs from $\mathrm{B}$ and S DNAPLs samples used. Table S3: Experimental conditions of the solubility tests carried out. wORGo $=400 \mathrm{mg}, \mathrm{Vaq}=0.02 \mathrm{~L}, \mathrm{pH}=7$ and $>12\left(7 \mathrm{~g} \mathrm{~L}^{-1} \mathrm{NaOH}\right) ;$ DNAPL: B and S. Table S4: Parameters and statically significance obtain to fit Equations (4) and (5) to the data in Figure 1 at $\mathrm{pH}=7$ and $\mathrm{pH}>12$ for both DNAPLs, $\mathrm{B}$ and S. Table S5: Concentrations of surfactants and COCs in aqueous phase at neutral and alkaline $\mathrm{pH}$ and equilibrium state. Table S6: Parameters and statically significance obtain to fit Equation (9) to the data in Figure 4 at $\mathrm{pH}=7$ and $\mathrm{pH}>12$ for both DNAPLs, $\mathrm{B}$ and S. Figure S1: Left: organic phase S; right: organic phase B adding E3 at several concentrations (initial surfactant concentration from the left to the right: 3, 5, 7.5, and $15 \mathrm{~g} \mathrm{~L}^{-1}$ ) and $\mathrm{pH}=7$. Top: Appearance before agitation. Center: Appearance after agitation $(5 \mathrm{~h})$. Bottom: Appearance after $75 \mathrm{~h}$ of settling. Figure S2: Left: organic phase S; right: organic phase B adding T80 at several concentrations (initial surfactant concentration from the left to the right: $3,5,7.5$, and $15 \mathrm{~g} \mathrm{~L}^{-1}$ ) and $\mathrm{pH}=7$. Top: Appearance before agitation. Center: Appearance after agitation $(5 \mathrm{~h})$. Bottom: Appearance after $75 \mathrm{~h}$ of settling. Figure S3: Left: organic phase S; right: organic phase B adding TS80 at several concentrations (initial surfactant concentration from the left to the right: $3,5,7.5$, and $15 \mathrm{~g} \cdot \mathrm{L}^{-1}$ ) and $\mathrm{pH}=7$. Top: Appearance before agitation. Center: Appearance after agitation $(5 \mathrm{~h})$. Bottom: Appearance after $75 \mathrm{~h}$ of settling. Figure S4: Left: organic phase S; right: organic phase B adding SDS at several concentrations (initial surfactant concentration from the left to the right: 3,5 , 7.5, and $15 \mathrm{~g} \mathrm{~L}^{-1}$ ) and $\mathrm{pH}=7$. Top: Appearance before agitation. Center: Appearance after agitation (5 h). Bottom: Appearance after $75 \mathrm{~h}$ of settling. Figure S5: Appearance of emulsion at $75 \mathrm{~h}$ of settling after alkali addition: from the top to the bottom: E3, T80, TS80, and SDS. Left: Results with DNAPL from S, right: Results with B. Initial surfactant concentration from the left to the right: $3,5,7.5$, and $15 \mathrm{~g} \cdot \mathrm{L}^{-1}$. Figure S6: Molar distribution (\%) of COCs in the initial DNAPL: $B$ as sum of isomers and COCs distribution in aqueous phase using a surfactant initial concentration of (a) $C_{\text {surf, } A Q 0}=3 \mathrm{~g} \cdot \mathrm{L}^{-1}$ (b) $\mathrm{C}_{\text {surf, } \mathrm{AQ} 0}=15 \mathrm{~g} \cdot \mathrm{L}^{-1}$ at $\mathrm{pH}>12$. Figure S7: Molar distribution (\%) of COCs in the initial DNAPL: $S$ as sum of isomers and COCs distribution in aqueous phase using a surfactant initial 
concentration of (a) $C_{\text {surf,AQ0 }}=3 \mathrm{~g} \cdot \mathrm{L}^{-1}$ (b) $C_{\text {surf,AQ0 }}=15 \mathrm{~g} \cdot \mathrm{L}^{-1}$ at $\mathrm{pH}>12$. Figure S8: Reaction of HCH and PentaCX isomers in DNPLS to TCBs under alkali conditions adapted from (Lorenzo et al., 2020). Figure S9. Reaction of HeptaCH and HexaCX isomers in DNPLS to TetraCBs under alkali conditions. Adapted from (Lorenzo et al., 2020).

Author Contributions: Conceptualization, A.R., A.S., and D.L.; data curation, R.G.-C. and D.L.; funding acquisition, A.R. and A.S.; investigation, R.G.-C. and D.L.; methodology, R.G.-C. and A.S.; supervision, A.S. and D.L.; writing-original draft, R.G.-C.; writing-review \& editing, A.S. and D.L. All authors have read and agreed to the published version of the manuscript.

Funding: This research was supported by the EU LIFE Program (LIFE17 ENV/ES/000260), the Regional Government of Madrid, through the CARESOIL project (S2018/EMT-4317), and the Spanish Ministry of Economy, Industry and Competitiveness, through project CTM2016-77151-C2-1-R. Raúl García-Cervilla acknowledges the Spanish FPI grant (ref. BES-2017-081782).

Acknowledgments: The authors thank the Department of Agriculture, Livestock and the Environment, Government of Aragon, Spain, as well as EMGRISA, for kindly supplying the samples.

Conflicts of Interest: The authors declare no conflict of interest.

\section{References}

1. van Liedekerke, M.; Prokop, G.; Rabl-Berger, S.; Kibblewhite, M.; Louwagie, G. Progress in the Management of Contaminated Sites in Europe; Reference Report; Joint Research Centre of The European Union: Ispra, Italy, 2014.

2. Siegrist, R.L.; Crimi, M.; Simpkin, T.J. Situ Chemical Oxidation for Groundwater Remediation; Springer: New York, NY, USA, 2011. [CrossRef]

3. Sulaymon, A.H.; Gzar, H.A. Experimental investigation and numerical modeling of light nonaqueous phase liquid dissolution and transport in a saturated zone of the soil. J. Hazard. Mater. 2011, 186, 1601-1614. [CrossRef] [PubMed]

4. Soga, K.; Page, J.W.; Illangasekare, T.H. A review of NAPL source zone remediation efficiency and the mass flux approach. J. Hazard. Mater. 2004, 110, 13-27. [CrossRef] [PubMed]

5. Parker, B.L.; Bairos, K.; Maldaner, C.H.; Chapman, S.W.; Turner, C.M.; Burns, L.S.; Plett, J.; Carter, R.; Cherry, J.A. Metolachlor dense non-aqueous phase liquid source conditions and plume attenuation in a dolostone water supply aquifer. In Groundwater in Fractured Bedrock Environments: Managing Catchment and Subsurface Resources; Ofterdinger, U., Macdonald, A.M., Comte, J.C., Young, M.E., Eds.; Geological Sociaty of London: London, UK, 2019; Volume 479, pp. 207-236.

6. Santos, A.; Fernandez, J.; Guadano, J.; Lorenzo, D.; Romero, A. Chlorinated organic compounds in liquid wastes (DNAPL) from lindane production dumped in landfills in Sabinanigo (Spain). Environ. Poll. 2018, 242, 1616-1624. [CrossRef] [PubMed]

7. Fernández, J.; Arjol, M.; Cacho, C. POP-contaminated sites from HCH production in Sabiñánigo, Spain. Environ. Sci. Pollut. Res. 2013, 20, 1937-1950. [CrossRef] [PubMed]

8. Council, N.R. Alternatives for Managing the Nation's Complex Contaminated Groundwater Sites; National Academies Press: Washington, DC, USA, 2013.

9. Agaoglu, B.; Copty, N.K.; Scheytt, T.; Hinkelmann, R. Interphase mass transfer between fluids in subsurface formations: A review. Adv. Water Resour. 2015, 79, 162-194. [CrossRef]

10. Brusseau, M.L. The Impact of DNAPL Source-Zone Architecture on Contaminant Mass Flux and Plume Evolution in Heterogeneous Porous Media; ARIZONA UNIV TUCSON: Tucson, AZ, USA, 2013.

11. Schaefer, C.E.; White, E.B.; Lavorgna, G.M.; Annable, M.D. Dense Nonaqueous-Phase Liquid Architecture in Fractured Bedrock: Implications for Treatment and Plume Longevity. Environ. Sci. Technol. 2016, 50, 207-213. [CrossRef]

12. Kavanaugh, M.C.; Suresh, P.; Rao, C. The DNAPL Remediation Challenge: Is there a Case for Source Depletion; Environmental Protection Agency: Washington, DC, USA, 2003.

13. McGuire, T.M.; McDade, J.M.; Newell, C.J. Performance of DNAPL source depletion technologies at 59 chlorinated solvent-Impacted sites. Groundw. Monit. Remediat. 2006, 26, 73-84. [CrossRef]

14. Atteia, O.; Estrada, E.D.; Bertin, H. Soil flushing: A review of the origin of efficiency variability. Rev. Environ. Sci. Bio. Technol. 2013, 12, 379-389. [CrossRef] 
15. Strbak, L. Situ Flushing with Surfactants and Cosolvents; National Network of Environmental Studies Fellowship Report for US Environmental Protection Agency; Office of Solid Waste and Emergency Response Technology Innovation Office: Washington, DC, USA, 2000.

16. Svab, M.; Kubala, M.; Muellerova, M.; Raschman, R. Soil flushing by surfactant solution: Pilot-scale demonstration of complete technology. J. Hazard. Mater. 2009, 163, 410-417. [CrossRef]

17. Pennell, K.D.; Capiro, N.L.; Walker, D.I. Surfactant and cosolvent flushing. In Chlorinated Solvent Source Zone Remediation; Kueper, B.H., Stroo, H.F., Vogel, C.M., Ward, C.H., Eds.; Springer: New York, NY, USA, 2014; Volume 7, pp. 353-394.

18. Maire, J.; Joubert, A.; Kaifas, D.; Invernizzi, T.; Marduel, J.; Colombano, S.; Cazaux, D.; Marion, C.; Klein, P.Y.; Dumestre, A.; et al. Assessment of flushing methods for the removal of heavy chlorinated compounds DNAPL in an alluvial aquifer. Sci. Total Environ. 2018, 612, 1149-1158. [CrossRef]

19. Londergan, J.; Yeh, L. Surfactant-Enhanced Aquifer Remediation (SEAR) Implementation Manual; INTERA INC.: Austin, TX, USA, 2003.

20. Acosta, E.J.; Quraishi, S. Surfactant Technologies for Remediation of Oil Spills. In Oil Spill Remediation: Colloid Chemistry-Based Principles and Solutions; Somasundaran, P., Patra, P., Farinato, R.S., Papadopoulos, K., Eds.; Wiley \& Sons: Hoboken, NJ, USA, 2014; pp. 317-358.

21. Mulligan, C.; Yong, R.; Gibbs, B. Surfactant-enhanced remediation of contaminated soil: A review. Eng. Geol. 2001, 60, 371-380. [CrossRef]

22. Besha, A.T.; Bekele, D.N.; Naidu, R.; Chadalavada, S. Recent advances in surfactant-enhanced In-Situ Chemical Oxidation for the remediation of non-aqueous phase liquid contaminated soils and aquifers. Environ. Technol. Innov. 2018, 9, 303-322. [CrossRef]

23. Rosen, M.J.; Kunjappu, J.T. Surfactants and Interfacial Phenomena; John Wiley \& Sons: Hoboken, NJ, USA, 2012.

24. Mukerjee, P.; Mysels, K.J. Critical Micelle Concentrations of Aqueous Surfactant Systems; National Standard Reference Data system: Washington, DC, USA, 1971.

25. Mao, X.; Jiang, R.; Xiao, W.; Yu, J. Use of surfactants for the remediation of contaminated soils: A review. J. Hazard. Mater. 2015, 285, 419-435. [CrossRef]

26. Swe, M.M.; Yu, L.Y.E.; Hung, K.C.; Chen, B.H. Solubilization of selected polycyclic aromatic compounds by nonionic surfactants. J. Surfactants Deterg. 2006, 9, 237-244. [CrossRef]

27. Bouzid, I.; Maire, J.; Brunol, E.; Caradec, S.; Fatin-Rouge, N. Compatibility of surfactants with activated-persulfate for the selective oxidation of PAH in groundwater remediation. J. Environ. Chem. Eng. 2017, 5, 6098-6106. [CrossRef]

28. Sharmin, R.; Ioannidis, M.A.; Legge, R.L. Effect of nonionic surfactant partitioning on the dissolution kinetics of residual perchloroethylene in a model porous medium. J. Contam. Hydrol. 2006, 82, 145-164. [CrossRef] [PubMed]

29. Kibbey, T.C.G.; Chen, L.C. Phase volume effects in the sub- and super-CMC partitioning of nonionic surfactant mixtures between water and immiscible organic liquids. Colloid Surf. A 2008, 326, 73-82. [CrossRef]

30. Zimmerman, J.B.; Kibbey, T.C.G.; Cowell, M.A.; Hayes, K.F. Partitioning of ethoxylated nonionic surfactants into nonaqueous-phase organic liquids: Influence on solubilization behavior. Environ. Sci. Technol. 1999, 33, 169-176. [CrossRef]

31. Kang, S.; Lim, H.S.; Gao, Y.; Kang, J.; Jeong, H.Y. Evaluation of ethoxylated nonionic surfactants for solubilization of chlorinated organic phases: Effects of partitioning loss and macroemulsion formation. J. Contam. Hydrol. 2019, 223, 103475. [CrossRef]

32. Paria, S. Surfactant-enhanced remediation of organic contaminated soil and water. Adv. Colloid Interface Sci. 2008, 138, 24-58. [CrossRef]

33. Muff, J.; MacKinnon, L.; Durant, N.D.; Bennedsen, L.F.; Rugge, K.; Bondgaard, M.; Pennell, K.D. Solubility and reactivity of surfactant-enhanced alkaline hydrolysis of organophosphorus pesticide DNAPL. Environ. Sci. Pollut. Res. 2020, 27, 3428-3439. [CrossRef] [PubMed]

34. West, C.C.; Harwell, J.H. Surfactants and subsurface remediation. Environ. Sci. Technol. 1992, 26, $2324-2330$. [CrossRef]

35. Babaei, M.; Copty, N.K. Numerical modelling of the impact of surfactant partitioning on surfactant-enhanced aquifer remediation. J. Contam. Hydrol. 2019, 221, 69-81. [CrossRef] [PubMed] 
36. Cowell, M.A.; Kibbey, T.C.G.; Zimmerman, J.B.; Hayes, K.F. Partitioning of ethoxylated nonionic surfactants in water/NAPL systems: Effects of surfactant and NAPL properties. Environ. Sci. Technol. 2000, 34, 1583-1588. [CrossRef]

37. Yang, J.-S.; Yang, J.-W. Partitioning effects of nonionic surfactants on the solubilization of single or binary chlorinated solvents: Batch and column experiments. J. Ind. Eng. Chem. 2018, 58, 140-147. [CrossRef]

38. Catanoiu, G.; Carey, E.; Patil, S.R.; Engelskirchen, S.; Stubenrauch, C. Partition coefficients of nonionic surfactants in water/n-alkane systems. J. Colloid Interface Sci. 2011, 355, 150-156. [CrossRef]

39. Lorenzo, D.; García-Cervilla, R.; Romero, A.; Santos, A. Partitioning of chlorinated organic compounds from dense non-aqueous phase liquids and contaminated soils from lindane production wastes to the aqueous phase. Chemosphere 2020, 239, 124798. [CrossRef]

40. Casado, I.; Mahjoub, H.; Lovera, R.; Fernandez, J.; Casas, A. Use of electrical tomography methods to determinate the extension and main migration routes of uncontrolled landfill leachates in fractured areas. Sci. Total Environ. 2015, 506, 546-553. [CrossRef]

41. Navarro, J.S.; López, C.; García, A.P. Characterization of groundwater flow in the Bailin hazardous waste-disposal site (Huesca, Spain). Environ. Geol. 2000, 40, 216-222. [CrossRef]

42. Rhue, R.D.; Rao, P.S.C.; Annable, M.D. Single-phase microemulsification of a complex light-nonaqueous-phase-liquid: Laboratory evaluation of several mixtures of surfactant alcohol solutions. J. Environ. Qual. 1999, 28, 1135-1144. [CrossRef]

43. Cheng, M.; Zeng, G.; Huang, D.; Yang, C.; Lai, C.; Zhang, C.; Liu, Y. Advantages and challenges of Tween 80 surfactant-enhanced technologies for the remediation of soils contaminated with hydrophobic organic compounds. Chem. Eng. J. 2017, 314, 98-113. [CrossRef]

44. Franzetti, A.; Di Gennaro, P.; Bevilacqua, A.; Papacchini, M.; Bestetti, G. Environmental features of two commercial surfactants widely used in soil remediation. Chemosphere 2006, 62, 1474-1480. [CrossRef] [PubMed]

45. Muherei, M.A.; Junin, R.; Bin Merdhah, A.B. Adsorption of sodium dodecyl sulfate, Triton X100 and their mixtures to shale and sandstone: A comparative study. J. Pet. Sci. Eng. 2009, 67, 149-154. [CrossRef]

46. Corcho, D.; Fernández, J.; Laperou, L.; Guadaño, J. Laboratory evaluation of mixed surfactants solutions to mobilise hexachlorocyclohexane (DNAPL) from sardas landfill (Aragón, Spain). In Proceedings of the 13th HCH \& Pesticides Forum, Zaragoza, Spain, 3-6 Novermber 2015.

47. Tsaboula, A.; Papadakis, E.-N.; Vryzas, Z.; Kotopoulou, A.; Kintzikoglou, K.; Papadopoulou-Mourkidou, E. Environmental and human risk hierarchy of pesticides: A prioritization method, based on monitoring, hazard assessment and environmental fate. Environ. Int. 2016, 91, 78-93. [CrossRef]

48. Willett, K.L.; Ulrich, E.M.; Hites, R.A. Differential toxicity and environmental fates of hexachlorocyclohexane isomers. Environ. Sci. Technol. 1998, 32, 2197-2207. [CrossRef]

49. Tsai, K.-P.; Chen, C.-Y. An algal toxicity database of organic toxicants derived by a closed-system technique. Environ. Toxicol. Chem. 2007, 26, 1931-1939. [CrossRef]

50. van Wijk, D.; Cohet, E.; Gard, A.; Caspers, N.; van Ginkel, C.; Thompson, R.; de Rooij, C.; Garny, V.; Lecloux, A. 1,2,4-Trichlorobenzene marine risk assessment with special emphasis on the Osparcom region North Sea. Chemosphere 2006, 62, 1294-1310. [CrossRef]

51. Zhou, M.F.; Rhue, R.D. Screening commercial surfactants suitable for remediating DNAPL source zones by solubilization. Environ. Sci. Technol. 2000, 34, 1985-1990. [CrossRef]

52. Pei, G.P.; Zhu, Y.E.; Cai, X.T.; Shi, W.Y.; Li, H. Surfactant flushing remediation of o-dichlorobenzene and p-dichlorobenzene contaminated soil. Chemosphere 2017, 185, 1112-1121. [CrossRef]

(C) 2020 by the authors. Licensee MDPI, Basel, Switzerland. This article is an open access article distributed under the terms and conditions of the Creative Commons Attribution (CC BY) license (http://creativecommons.org/licenses/by/4.0/). 